\title{
Hace 75 años
}

\section{La lucha contra la desnutrición infantil}

Publicado en Revista Chilena de Pediatría 1936: 7(1): 1-6.

\author{
Autor: EUGENIO CIENFUEGOS ${ }^{1}$ \\ Comentario:LUISA SCHONHAUT B. ${ }^{2}$ \\ 1. Profesor Titular de Clínica Pediátrica. \\ 2. Profesor Asistente, Magíster Salud Pública, Departamento de Pediatría Norte, Facultad de Medicina, \\ Universidad de Chile.
}

Palabras clave: nutrición infantil, desnutrición, distrepsia, deprivación psicosocial, hospitalismo.

Key words: child nutrition, undernutrition, psychosocial deprivation, hospitalism.

\section{Introducción}

En los años 30 la mortalidad infantil era elevadísima, superando las 200 muertes por cada 1000 nacidos vivos ${ }^{1}$. Las principales causas de morbimortalidad se relacionaban con las enfermedades infectocontagiosas y la desnutrición o distrofia. Múltiples son los artículos publicados hace 75 años que dan fe de la preocupación de los pediatras por la nutrición infantil:

"Pocos problemas hay que interesen más al pediatra que aquellos que se refieren a la dietética infantil. Es un hecho ya consagrado por la pediatría que la salud del niño depende en gran parte de la perfecta adaptación entre el alimento y su organismo. Sucede sin embargo, que muchos niños colocados en las mejores condiciones higiénicas, libres de toda infección y sometidos a una alimentación estrictamente reglamentada a su edad, no progresan como lo hacen la mayor parte de ellos.
Algunos parecen ser afectados en su nutrición general, tienen trastornos crónicos o afecciones mejor definidas como anemia, diátesis exudativa, neuropática, raquitismo, eczema, tetania, etc. o por fin presentan fenómenos de idiosincrasia con un estado constitucional especial que los predispone a padecer de ciertas enfermedades. Por fin queda otro grupo de lactantes, que siendo constitucionalmente sanos se han hecho distróficos a consecuencia de infecciones repetidas o de un error higiénico dietético prolongado." (Matte R 1930)2.

"La distrofia, su patogenia y su tratamiento, constituyen para la pediatría, uno de los problemas de más alto interés científico y uno de los capítulos de mayor valor práctico.

Palpados los fracasos de nuestros conocimientos y la escasez de los recursos dietetoterapéuticos ante un sinnúmero de distróficos que fallecian irremediablemente, a pesar de nuestros mayores esfuerzos, hemos ido separando, en el gran grupo de distróficos, que eran atendidos en el servicio de lactantes del Hospital de niños M. Arriarán, dos clases de este trastorno nutritivo, unos que se corregían simple y fácilmente con la modificación adecuada de sus regimenes y otros que sucumbian a pesar del mayor cuidado en su dietética. 
En el segundo grupo, que podría llamarse de los dieteto-resistentes nos llamó la atención la presencia de una inmunidad sumamente baja, o sea una resistencia mínima frente a las infecciones. Dicho estado del lactante que padece de un trastorno nutritivo crónico, depende muy a menudo, además de su alteración gastrointestinal y del metabolismo intermediario, exclusivamente de un desequilibrio más o menos intenso en el metabolismo de todo su complejo celular, o sea del receptor final de todos los elementos nutritivos. Constitucional o adquirido, la corrección de este defecto determinante o coadyuvante de la distrofia, tiene que ser en muchos casos tanto o más importante que la reglamentación de una terapéutica dietética muy bien indicada." (C. Santibáñez 1930)․․

En la incansable lucha contra las distrepsias, se realizaron ensayos con múltiples tratamientos y formulaciones para la nutrición infantil: las fórmulas sin leche ${ }^{2}$, las leches de albuminosa "cuando nuestros pediatras comenzaban hace ya algunos años a posesionarse del concepto patogénico de los trastornos nutritivos en el lactante, la leche albuminosa reinaba sin competidores como elemento dietético terapéutico heroico en el tratamiento de esas afecciones" (J. Schwarzenberg y A. Steeger 1930)", el babeurre "Como con el tiempo fuéramos observando que en el tratamiento de los trastornos nutritivos del lactante, en general los resultados obtenidos con el babeurre eran superiores a los que se obtenian con la leche albuminosa, la prescripción de esta última se ha ido restringiendo a ciertas dispepsias leves y a una alimentación transitoria en los trastornos crónicos con manifestaciones fermentativas preponderantes. Esta circunstancia ha ido aumentando enormemente el consumo del babeurre en todos nuestros Servicios de Lactantes y con esto se presentaba para nuestro Hospital un problema económico grave, que no tenía otra solución que la preparación de un babeurre siempre igual en calidad, composición y acidez." (J. Schwarzenberg y A Steeger 1930)5. Se ensayó incluso con las transfusiones sanguíneas en aquellos niños en que no era posible usar la vía enteral. “... en los que hemos deno- minado dieteto-resistentes (discompuestos y descompuestos) debemos procurar no alterar más aún la digestión ni la asimilación porque clínicamente no podemos formarnos un juicio cabal sobre la alteración exacta del organismo. En este caso tan delicado debemos mantener el equilibrio del niño y procurar con paciencia la reparación que se hace lentamente. Pero, además, contamos con la otra vía; la vía paraenteral. Por ella tratamos de modificar el estado celular con la aplicación de diversos estímulos. Así tenemos la terapéutica con sueros, específicos o no (antidiftérico, hemostyl) con lipoides (omnadina) o con proteinas (leche, vacunas).

Posteriormente se ha aplicado la inyección intramuscular de sangre humana (hemoterapia). Variando ahora la vía de introducción de la sangre hemos llegado a la transfusión sanguinea que podemos hacerla por vía intraperitoneal o directamente intravenosa. Es así, como después de muchos $y$ largos ensayos con todo el arsenal de la terapéutica de estimulación, con los que comenzamos a tratar ese estado de citolabildad de estos distróficos y cuyos resultados fueron en general poco alentadores, pasamos sin titubear al uso sistemático de las transfusiones sanguíneas en todos aquellos casos que eran catalogados como de mayor gravedad." (C. Santibáñez 1930)․․

Una de las grandes limitantes, según refieren los autores, era reproducir idénticamente aquellas formulaciones que resultaban tan exitosas según las experiencias reportadas por diversos autores extranjeros.

Hoy sabemos que el crecimiento es un proceso multifactorial, en que intervienen variables nutricionales, genéticas, hormonales y ambientales $^{6}$. Al demostrarse la importancia de la estimulación neurosensorial en el crecimiento y desarrollo infantil y el riesgo del tratamiento de la desnutrición en los centros hospitalarios, debido a las infecciones nosocomiales y la falta del personal suficiente para la alimentación y estimulación de los niños ${ }^{7}$, se comenzaron los esfuerzos por el manejo ambulatorio de la desnutrición y las políticas de Salud Pública para la prevención de la misma. En la década de los 50 se implementaron programas de alimentación 
complementaria y en los 70 se crearon los Centros de Nutrición para el estudio y la recuperación nutricional (CONIN CREDES) ${ }^{8}$.

Gracias a la implementación de las medidas descritas, en nuestro país la desnutrición infantil se ha convertido ya casi en leyenda. Las tasas actuales de desnutrición del niño menor de 6 años son inferiores al $0,5 \%$, la mayoría de las cuales corresponde a formas leves ${ }^{9}$. La transición epidemiológica nos ha enfrentado, a pasos agigantados, a un nuevo escenario epidemiológico, en que la reina es la obesidad ${ }^{10}$ y sus desfavorables consecuencias para la salud.

El diagnóstico de retraso de crecimiento suele ser complejo, debiendo diferenciar en su patogenia causas primarias y las secundarias a otras patologías; considerando, habitualmente por descarte, los trastornos de crecimiento de origen no orgánico, término conocido en la literatura anglosajona como "failure to thrive".

"No pienso que las perturbaciones digestivas y nutritivas del lactante puedan tener una clasificación definitiva; la experiencia, las nuevas adquisiciones científicas irán exigiendo nuevas y mejores agrupaciones de cuadros patológicas. Me parece, si, que para la enseñanza de este capitulo trascendental conviene tener un esquema que ha de variar sin duda de una época a otra, pero que debe refundir en un momento dado los conocimientos que se tengan sobre su patogenia para asi poder instituir orientaciones terapéuticas.

... Yo divido la patología digestiva en esta edad en dos capítulos: perturbaciones digestivo-nutritivas o sea aquellas en que el alimento, estimulo normal de la nutrición tiene papel preponderante y $2^{\circ}$ en infecciones gastro-intestinales del lactante o sea aquellas afecciones en que la infección es local con proyecciones o sin ellas hacia la nutrición.

Es claro que la infección tiene su papel y muy importante en la eclosión del trastorno nutritivo puro, pero ya no con los caracteres locales y limitados de este segundo acápite de clasificación. Habrá también formas mixtas que según sea la sintomatología dominante deben entrar en una u otra de las dos divisiones principales.

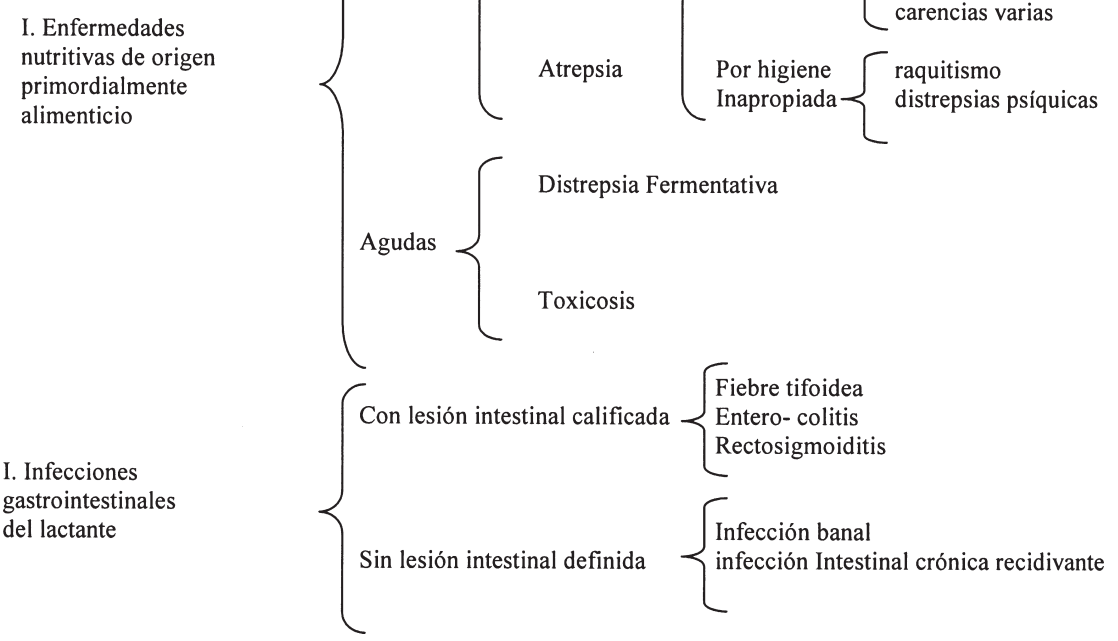

Figura 1. Enfermedades nutritivas y gastrointestinales del lactante ${ }^{1}$. 
El grupo primero, o sea, los trastornos nutritivos propiamente tales quedan divididos en crónicos y agudos y aquellos en distrepsia y atrepsia. Ambos pueden deberse a cantidad inadecuada, a calidad inadecuada o a higiene defectuosa. Entre los primeros tenemos aquellos que se producen por cantidad exagerada o por insuficiencia (distrepsias de hiper o de hipo alimentación).

Por calidad inadecuada tenemos a) la distrepsia de leche de vaca; b) la distrepsia de harinas; c) la distrepsia de avitaminosis $y$ d) la distrepsia por otras carencias (iones diversos, hormonas, amino-ácidos, etc.). Los trastornos por higiene defectuosa serían los que se atribuyan a carencia de ambiente afectivo (distrepsia de orden psíquico) y las por falta de luz o de condiciones higiénicas satisfactorias (figura 1)"11 (E. Cienfuegos 1931).

El Dr. Cienfuegos fue un connotado Profesor de Pediatría de la Universidad de Chile, socio fundador de la Sociedad Chilena de Pediatría el año $1922^{12}$ y presidente de la misma durante los períodos de 1923 y 1929-1930. En 1930, siendo presidente de la Sociedad, lanzó el primer número de la Revista Chilena de Pediatría ${ }^{13}$. En el primer artículo publicado, el Dr. Cienfuegos formula una interesantísima reflexión en relación al mundo psíquico y los afectos en la nutrición infantil.

\section{Referencias}

1.- Calvo Mackenna L: La mortalidad infantil en Chile: Estudiada por la Sociedad de las Naciones. Rev Chil Pediatr 1930; 1: 281-304, 55-78, 411-23.

2.- Matte Larrain R: Los regimenes sin leche en la primera infancia. Rev Chil Pediatr 1930; 1: 161-77.
3.- Santibáñez $C$ : La transfusión sanguínea en las distrofias del lactante. Rev Chil Pediatr 1930; 1: 128-33.

4.- Schwarzenberg J, Steeger A: ¿Cómo preparamos la leche albuminosa? Rev Chil Pediatr 1930; 1: 618-28.

5.- Schwarzenberg J, Steeger A: La preparación del babeurre en el hospital. Rev Chil Pediatr 1930; 1: 557-66.

6.- Muzzo S: Crecimiento normal y patológico del niño y del adolescente. Rev Chil Nutr, 2003; 30: 92-100. [citado 11 Julio 2007] Disponible en la World Wide Web: http://www.scielo.cl/scielo.php?Script=sci 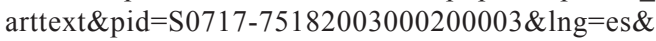 $\mathrm{nrm}=$ iso

7.- Muzzo S: Evolución de los problemas nutricionales en el mundo. El caso de Chile. Rev Chil Nutr 2002; 29: 78-85. [citado 11 Julio 2007] Disponible en la World Wide Web: http://www.scielo.cl/scielo.php?Script= sci_arttext\&pid=S0717-75182002000200001\&lng= es\&nrm=iso

8.- Valiente $S$, Uauy R: Evolución de la nutrición y alimentación en Chile en el siglo XX. Rev. Chil Nutr 2002; 29: 54-61. [citado 11 Julio 2007]. Disponible en la World Wide Web: http://www.scielo.cl/ scielo.php?Script $=$ sci_arttext\&pid $=$ S0717-7518200 2000100008\&lng=es\&nrm=iso

9.- Araya H, Atalah E, Benavides X, et al: Prioridades de intervención en alimentación y nutrición en Chile. Rev Chil Nutr 2006; 33: 458-63. [citado 11 Julio 2007], p.458-463. Disponible en la World Wide Web: http://www.scielo.cl/scielo.php?Script=sci_arttext\&pid= S0717-75182006000500001\&lng=es\&nrm=iso

10.- Kain J, Uauy R, Lera L, et al: Evolución del estado del estado nutricional de escolares chilenos de 6 años (1987-2003). Rev Méd Chile 2005; 133: 1013-20. [citado 11 Julio 2007] Disponible en la World Wide Web: http://www.scielo.cl/scielo.php?Script=sci_arttext \&pid=S0034-98872005000900003\&lng=es\&nrm=iso

11.- Cienfuegos E: Clasificación de los trastornos nutritivos del lactante. Rev Chil Pediatr 1931; 1: 11-7.

12.- Vargas $N$ : Historia de la Sociedad chilena de Pediatría. [citado el 11 julio 2007] http://www.sochipe.cl/nueva/ html/es-sociedad-historia.htm

13.- Vargas $N$ : Historia de la pediatría chilena: crónica de una alegría. Editorial Universitaria. Santiago de Chile 2002. 


\section{Distrepsias de origen psíquico}

\author{
EUGENIO CIENFUEGOS \\ 1. Profesor Titular de Clínica Pediátrica. \\ Rev Chil Pediatr 1930; 1 (1): 6-10
}

Hemos creído útil y conveniente insistir sobre algunas consideraciones acerca de cierto grupo de trastornos nutritivos crónicos hasta ahora escasamente estudiados y que según nuestro modo de pensar adquieren, sobre todo en los asilos de lactantes, una importancia practica considerable; nos referimos a aquellas perturbaciones nutritivas que se observan en todos aquellos casos en que el lactante sufre una depresión de su estado psíquico por impresiones morales repetidas, por carencia, podríamos decir, del ambiente amable, cariñoso que lo envuelve aún en el seno de familias cuyas condiciones económicas no son en absoluto envidiables. Tenemos con frecuencia el caso, sobre todo en los hogares proletarios, de criaturas que una vez que falta la persona que las rodeaba de cariño, de mimo, de atenciones, de cuya mano recibían el alimento y en cuyos ojos siempre encontraban una sonrisa, que conocía sus pequeños caprichos y se doblegaba a sus precoces tiranías, empiezan a sufrir manifiestamente en su desarrollo orgánico y funcional. $\mathrm{Su}$ habitual alegría desaparece, su apetito disminuye más y más, su color rosado se torna en palidez, sus curvas ponderal y estatural se detienen y poco a poco, sin que ninguna afección orgánica explique ese paulatino retroceso, se establece un proceso de consunción que muchas veces lleva al niño a la definitiva atrepsia como en los demás desórdenes crónicos de la nutrición. Nada ha cambiado en el régimen de comidas, ni en sus horas ni en su calidad; muchas veces con un poco de empeño se consigue vencer la anorexia frecuente en estos enfermitos hasta proporcionarles la cantidad con que antes de la instalación del proceso psíquico progresaban satisfactoriamente. Y sin embargo, la distrofia avanza, la inmunidad disminuye, la tolerancia se reduce a límites cada vez ma- yores y vemos fatalmente al niño marchar a la definitiva descomposición. Es este cuadro tan conocido por la sabiduría popular bajo el nombre de pensión el que nosotros creemos que debe ingresar al conjunto de los trastornos nutritivos crónicos bajo la denominación de distrepsias psíquicas o emotivas.

Y de la misma manera que Mouriquand ha hablado de enfermedades de carencia al estudiar las avitaminosis y Woringer de carencia solar al estudiar el raquitismo justo nos parece describir el grupo de trastornos que venimos estudiando en analogía a las anteriores con el nombre de distrepsias de carencia afectiva. La prueba de que es sólo el factor psíquico el que origina el cuadro la tenemos palpable si recordamos que una vez que el olvido, ha borrado piadosamente el recuerdo de la persona ida, cuando otro afecto ha sustituido al ya perdido, cuando alguien viene a reemplazar al ausente satisfaciendo los caprichos del enfermo, siguiendo sus gustos, acomodándose a sus hábitos, sin cambio alguno en el régimen alimenticio, la nutrición vuelve rápidamente a reanudar su seguro avance hacia la normalidad del desarrollo infantil.

Este mismo cuadro observado con relativa frecuencia en el hogar pobre en donde el afecto maternal o de una guardadora cariñosa se reemplaza con mucha dificultad, no como ocurre en la familia acomodada en que las facilidades de la existencia rodean con mayor frecuencia y con menos sacrificio de un ambiente amable al niño, es según nuestra opinión el que produce en los asilos de lactantes la enorme morbilidad y la gran mortalidad de los pequeños protegidos.

Entramos aquí a emitir nosotros también una opinión en este complicado y discutido tema del hospitalismo.

Sabemos que bajo esa denominación se ha entendido siempre la distrofia del niño asilado durante algún tiempo y que consiste en la detención de desarrollo de la criatura, su propensión a recoger las más variadas infecciones sin que tengan éxito alguno los sistemas alimenticios que se instituyen con provecho en el ambiente familiar.

Estudiando esta debatida cuestión del hospitalismo Finkelstein llega a decir que para él, 
hospitalismo en su esencia es infección y si suprimimos ese factor en la nutrición defectuosa de los asilados, no sobra casi nada. Agrega en otro acápite de su obra que evitando complicaciones alimenticias graves durante las infecciones mediante una técnica alimenticia perfeccionada él lleva a la curación mayor número de niños mientras antes sucumbían debido a los trastornos nutritivos secundarios.

No piensa de igual modo, sin embargo, Schelbe quien ya en 1909, afirmaba que aun en las mejores condiciones de alimentación y de asepsia, disminuyendo en lo posible la transmisión de infecciones respiratorias por parte del personal, no conseguían otra cosa que obtener atróficos no complicados sin que nunca esos niños se pudieran comparar con aquellos sometidos al tratamiento en el hogar seguido por mujeres que gastaran solo regular cuidado.

Análogas ideas inspiran a Pfaundler, cuando expone más o menos las siguientes opiniones: la diferencia entre el cuidado del niño en la familia y en el hospital o en el asilo no descansa principalmente en la diferencia de calidad y de cantidad alimenticia sino sobre todo sobre bases que no pueden definirse con absoluta precisión ni demostrarse con cifras matemáticas; son las que el llama "imponderables en el cuidado del niño". Queremos aquí estampar la descripción de Pfaundler que define muy bien el síndrome que nosotros denominamos distrepsias psíquicas o emotivas: "nos encontramos ante una decadencia corporal que se evidencia en los casos ya avanzados por palidez permanente y exagerada, flojedad y sequedad de la piel y del tejido adiposo subcutáneo, por perdida de la elasticidad de la piel, alteración del tonus muscular que a menudo está aumentado. Esta decadencia no es la señal de un trastorno crónico de alimentación ya por leche o harinas ni de una afección orgánica determinada. ¿Cuánto tiempo transcurre hasta llegar a este punto? Según Pfaundler, el plazo es muy variable y como término medio probable el de la tercera semana de alejamiento del hogar. Desde esa época ya se hace notar la consecuencia más grave del hospitalismo, es decir la completa falta de defensa ante las infecciones y precisamente estas se desarrollan completamente desligadas de la naturaleza del régimen alimenticio. El niño des- de ese momento queda fuera de toda ley de alimentación y los diferentes regimenes se desacreditan en estos casos, aún los mejores constituidos, salvo el régimen de alimentación natural".

Nosotros llegamos aun más allá y creemos que el factor psíquico influye de tal manera que ni aun la leche de mujer consigue muchas veces evitar el fatal deslizamiento del lactante asilado hacia la descomposición y la atrepsia.

En nuestro Servicio de lactantes del Hospital Manuel Arriaran, la alimentación ordeñada no ha conseguido, muchas veces, vencer el avance del hospitalismo, salvo en los casos en que el factor psíquico ha obrado en favor de la criatura, ya porque esta se ha encariñado con su nodriza o ésta ha tenido el instinto de dar al enfermito la dulce ilusión del regazo cuya falta echaba de menos.

Vemos muchas veces salir del hospital, niños con tal distrepsia psíquica, llegados ya a los lindes de la atrepsia inevitable y que algún tiempo después vuelven a la consulta externa completa y rápidamente curados de la perturbación nutritiva que llegó a desalentarnos completamente en nuestro esfuerzo por salvar a la criatura. Bastó la incorporación de ésta al medio familiar, que no es el más libre de los factores infecciosos, para que todo el gravísimo cuadro patológico perdiera su trágico cariz. En la pieza antihigiénica del conventillo, en medio del hacinamiento y promiscuidad que caracterizan a nuestras familias proletarias, sin el meticuloso orden y método gastados en la alimentación del lactante durante su permanencia en servicios tan bien instalados como los de nuestro hospital, bastó el factor psíquico para equilibrar los perjuicios nutritivos producidos aún a costa de tantos cuidados como los que se prodigan en las clínicas. ¿Infección? Jamás podrá sumarse en la limpia sala del hospital atendido por un personal idóneo de enfermeras y con alimentos esterilizados, satisfactoriamente bien dosificados para cada criatura, según su peso y condiciones de desarrollo, un cúmulo de infecciones comparables a las que acechan a la criatura en el hogar de nuestro pueblo en que centenares de niños de todas las edades viven en la más íntima y a veces repugnante mescolanza. 
Las Gotas de Leche nos dan, por otra parte, la experiencia de un progreso constante en los niños atendidos allí y que provienen de las mismas esferas sociales que proporcionan el material hospitalario.

El trastorno nutritivo leve o mediano cura en la consulta externa o en la Gota de Leche con relativa rapidez; se arrastra y muchas veces llega a acabar con el pequeño asilado en el hospital aun en los casos en que gastamos la mayor asiduidad en la determinación del régimen higiénico y dietético del enfermito. Tenemos además la observación de que los pequeñuelos que conquistan la especial simpatía de la enfermera o de una cuidadora, simpatía que se traduce no por mejor régimen alimenticio sino por mayor calor afectuoso o compasión, saturada de cariño, vencen muy bien la siniestra amenaza del hospitalismo.

¿En que consiste ahora este factor psíquico? A nuestro modo de ver es la suma, por un lado, mimo, distracción de la mente infantil y por otro inteligencia para satisfacer las costumbres y caprichos emanados de la inquieta personalidad de la criatura. Tal pequeñuelo toma su alimento en determinada posición, ya sentado, ya recostado sobre el lecho o en brazos de su madre y siempre igual sin que nada le logre quitar tal hábito o costumbre. Aquel otro no aceptará su mamadera si no se la sirve en un frasco de forma determinada y con un chupete de tal color o consistencia. No hará su proceso digestivo en forma normal sino queda en una posición determinada en su cama, con tal luz, tal canción, con tal halo de cariño de parte de su madre.
En el medio hospitalario la sistematización de los útiles destinados a la clientela del servicio, la uniformidad de las horas, la variabilidad del personal, la monotonía de la sala, del horizonte que abarca la mirada del lactante, hacen que en un individuo en que aún no existe ni raciocinio ni control de la personalidad, esta carencia del ambiente afectuoso y dócil en que ha nacido y se ha criado el niño repercuta poderosamente sobre la función básica suya, la nutrición, que como ya lo hemos dicho sobradamente se afecta con cualquier factor de cualquiera índole que actué sobre la criatura.

Si en el individuo adulto que raciocina, que se sabe sobreponer sobre la adversidad, que se habitúa a todo porque la educación o el medio lo han enseñado a eso, el sufrimiento logra influir determinadamente sobre su funcionalismo orgánico ¿con cuánta mayor razón no ha de suceder cosa semejante en un organismo apenas iniciado en el complicado mecanismo de la vida, para quien no hay sino un fin, desarrollarse, y alrededor de cuya función fundamental, la nutrición, actúan constantemente todos los factores, químicos, físicos, morales o los que Pfaundler denomina "imponderables" en el cuidado de los niños?

Hospitalismo es, pues, para nosotros, en parte infección, en parte técnica alimenticia defectuosa, sobre todo, depresión psíquica, Ella altera la nutrición, disminuye su resistencia a las infecciones, restringe su tolerancia y de esta suerte el factor psíquico inicia la cadena cuyos eslabones consecutivos, infección y disminución de la tolerancia, atan al niño al carro fatal de la atrepsia. 